\title{
"The fully employed high income society": a comment
}

\author{
John Robinson*
}

An April 1990 Planning Council report The fully employed high income society, by Dennis Rose has received nationwide publicity due to its suggestion that full employment is possible by 1995 . The suggestion that full employment is possible within 5 years is based on several model experiments. In this paper I examine the calculations on which these assertions are based, and conclude that they are not supported; indeed the modelling indicates the very opposite of what is claimed - full employment by 1995 is next to impossible following current policies.

\section{The major conclusions of the report}

The major conclusions of the report are the first three items in the "Conclusion" list of p.38:

- Labour force forecasts suggest that New Zealand needs to increase employment by an average annual rate of close to 2.5 percent if it is to return to full employment by 1995 .

- The model suggests that faster rates of productivity increase will provide the fundamental basis for competitive expansions in output, employment and income.

- Thus, a doubling in sectoral rates of productivity increase (from those in Prospects) could lead, by 1995 , to full employment and to a level of GDP 15 percent higher than suggested in the base line medium-term forecasts.

The reference to Prospects is to a 1988 Planning Council report by the National Sectoral Programme with Dennis Rose as convenor (New Zealand Planning Council, 1988). The modelling of the later report has used the Prospects modelling as a base, and adjusted the input parameters to generate more optimistic forecasts. The models used in the two linked reports are SDMACRO, a system-dynamics macroeconomic model of the New Zealand economy; and JULIANNE, a non-linear general-equilibrium model, developed and run at the Project on Economic Planning, Victoria University.

\section{Required increases in employment}

Since the discussion takes the 1988 Prospects forecasts as a base, it is important to first note the forecasts of employment changes made there, and to compare the forecasts with the measured values. Employment is measured in full time equivalents derived from 
the March Household Labour Force Survey, with one part-time worker taken as the equivalent of half a full timer (New Zealand Planning Council, 1988, p.63). Since the values provided by the Department of Statistics do not correspond exactly with those of the Planning Council reports, changes in employment are compared over the two-year periods 1986-88 and 1988-90.

The 1988 forecast of Prospects commence in 1986, giving values of 1,391,000 in 1986, 1,415,000 in 1988 and 1,429,000 in 1990 (New Zealand Planning Council, 1988, infogram A3.1, p.91). Values of full and part time employment provided by the Department of Statistics for the March Household Labour Force Surveys indicate full time equivalents of $1,424,000$ in $1986,1,393,000$ in 1988 and $1,334,000$ in 1990 . Thus, even at the time of publication of this 1988 report the model was forecasting an employment increase of 24,000 over the previous two years when in fact employment had dropped by 31,000 . Subsequently the model has forecast a further employment increase of 14,000 in $1988-90$ whereas employment actually dropped by 59,000 . Thus over the 4 years 1986-88 (a significant period for such modelling) the model suggested an increase in employment of 38,000, whereas the actual experience was of a fall of 90,000.

The actual contraction in the job market is dismissed in the Fully employed high income society as follows:

\begin{abstract}
Events to date have been worse than forecast. Employment has fallen sharply over a period in which Prospects suggested a small increase. Participation rates have also fallen. At this stage we have assumed these are short-term responses to adverse conditions, and the Prospects forecasts are used to give an idea of the necessary growth in employment (Rose, 1990, p.2).
\end{abstract}

The 1990 report repeats the process of commencing calculations 2 years in the past, and ignoring the real-life drop in employment. The analysis of employment increases required to give "full" employment [defined as 2 percent "frictional" employment (Rose 1990, p.2)] is based on the statement that the actual 1988 employment of $1,357,000$ must be increased to $1,590,000$ by the year 1995 . This requires 33,000 new jobs a year, an increase at a rate of 2.3 percent per annum (Rose 1990, p.3 and infogram 1). This rate of increase is given as 2.5 percent in the conclusions (Rose, 1990, p.38). The difference between the 2 values noted is minimal and need not concern us here. The forecast and observed employment changes are summarised in table 1 .

Table 1: Employment changes

Period

Prospects 1988

Rose 1990

Observed

Forecasts

Forecasts

1986-88

1988-90

24,000

14,000

66,000

If the actual drop off in employment is taken into account, it is found that in order to create "full" employment by 1995 , starting from the present, 1990 , then 292,000 jobs must be created in 5 years - rather than 233,000 jobs in 7 years. This requires the creation of 58,400 jobs per year (not 33,000 ), an increase at a rate of 4.3 percent per year (not 2.3 percent or 2.5 percent). The statement, in the conclusions, of the number of jobs required depends on deliberately ignoring recent job losses, and requiring job creation to commence 2 years in the past. The first conclusion, that employment growth at an 
annual rate of 2.5 percent is needed if full employment is to be achieved by 1995 , does not hold true in 1990.

\title{
3. The modelling time-span
}

The third claim of the conclusion is that

\begin{abstract}
a doubling in sectoral rates of productivity increase (from those in Prospects) could lead, by 1995, to full employment and to a level of GDP 15 percent higher than suggested in the base line medium-term forecasts (Rose, 1990, p.38).
\end{abstract}

This would seem to indicate a doubling of productivity over the remaining 5-year period, 1990-95. However, as the following quotes make clear, the modelling commences in 1984 and covers an 11-year time span.

A doubling of the annual rate of productivity increase from 1 to 2 percent (sustained in the model run over an eleven-year period) would dramatically alter the competitiveness of New Zealand production by reducing the amounts of labour and capital required to produce any particular level of output (Rose, 1990, p.4).

\section{The projections are}

made from two linked models based in the mid 1980s over the span to 1994/95. The early years of that period are already history, but are not part of the written record available to the models (Rose, 1990, p.16).

The scale of this increase in GDP is, at first sight, surprising. It is less so when recognised that the model spans an eleven-year period. The annual differences in productivity gains compound to an 11 percent increase (Rose, 1990, p.17).

\section{Manipulating the model - and changes in capital stock}

The model is not however then left to follow those specifications alone, and to explore the consequences so far as employment is concerned. Rather, the model is instructed to reduce unemployment to the required figure.

Because some part of the increase in productivity is likely to result from
innovations embodied in new equipment, buildings and systems, it is assumed
that the capital stock available in the future reference year - 1995 - is 5 percent
higher than in the Prospects forecast. This requires a significant lift in capital
formation, given that we are now more than half way from the model's 1984
base to the 1995 "snapshot" year. Finally, the model is told to reduce the
unemployment rate to 2 percent of the available work force (Rose, 1990, p.17).

Much of the presentation suggests that the increase in capital stock is secondary to the productivity improvements. Thus, for example, the list of conclusions includes:

The model runs suggest that higher rates of investment would, by enlarging the nation's capital stock, and provided the investments were well chosen, make it easier to expand economic activity and employment (Rose, 1990, p.38). 
However, the increases in capital stock do not just "make it easier" to generate full employment, rather the complete increase in employment is generated from the increased capital alone.

In the model run just reported it was assumed that a doubling of sectoral productivity growth rates would require an increase in the capital stock available in the scenario year, and thus was arbitrarily set 5 percent above the levels that would otherwise prevail. The earlier run thus combines the effect of increased productivity and higher levels of capital.

The model was then used to sketch the outcome of an increase in the capital stock without a parallel doubling in the rate of technical change. This intermediate sketch helps to assess the relative strength of the two changes. .... The results are quite dramatic, as are the contrasts between the two variant runs. The first point to note is that the model was required to move to 'full employment' between the Prospects and 'higher capital stock' runs. Employment thus increases by 100 percent of the full increase secured by the combined influence of capital and productivity. .... In this run full employment is being secured without any significant shift in real incomes, solely through an expansion in the capital stock. The mechanism is clear enough. The required increase in employment is equivalent to 4.2 percent of the Prospects level. If by 1995 our capital stock was 5 percent larger than in Prospects, and provided that investment had been well placed in profitable uses, then there should in principle be little problem in providing additional employment in about the same proportion (Rose, 1990, p.19).

The output of reduced unemployment is not then a consequence of the modelling, but rather a requirement which was fed in at the outset. The model simply does what is told. It is clear that the model "was required" to give full employment by an "arbitrary" change in capital formation, with no change in productivity. It is then incorrect to claim that the productivity change will lead to such an employment increase.

There is little discussion of this arbitrary increase in capital formation, other than the comment that: "Given the low levels of investment in recent years, annual investment has to lift markedly from now on to support the required $\$ 8$ billion increase in capital stocks" (Rose, 1990, p.18).

The increase in capital formation which has been associated with the productivity increase points to some confusion concerning just what is meant by "productivity". Productivity is generally a residual factor, being what is left when the impacts of changes in labour and capital have been removed in a model formulation. It is a term which represents all those various factors which cannot be ascribed to readily measured labour and capital.

Productivity growth, technical change, and total factor productivity (TFP) are often seen as interchangeable terms describing that proportion of real output growth which comes from increased efficiency in the use of labour and capital inputs ( New Zealand Planning Council, 1988, p.33).

Measures of productivity (p), and of changes in productivity, are generated with the use of an appropriate formula relating output (Q) to the labour force employed (L) and the capital stock (C). Thus,

$$
Q=f(p) g(L, C)
$$

This may take the form

$$
Q=f(p) L^{\alpha} C^{1-\alpha} \text {, }
$$


and, if the productivity function is increasing at constant rate with time,

$$
\mathrm{Q}=\mathrm{A} \exp (\mathrm{cp}) \mathrm{L}^{\alpha} \mathrm{C}^{1-\alpha}
$$

This was the formula used at OECD Interfutures.

The impact of any change in productivity is then separate from changes due to capital formation. This can be seen in the Prospects figure illustrating the forecasting process (New Zealand Planning Council, 1988, p.8), where "capital stocks" and "technical change" are input quite separately into the JULLIANNE model.

The change in capital stock was an additional and independent exogenous change to the model run, and should have been clearly referenced as such. In this respect the headings on the charts (Rose, 1990) are significant, since it is only on infogram 6 that the heading for this run is "higher capital and productivity"; in other infograms the combined run is referred to under the heading "higher productivity" (as, for example, infograms 5 and 10, both of which note the considerable increases in employment which were in fact generated by the higher capital). This conveys the incorrect message to the reader that the changes in employment have been generated by the modelling of productivity. The second conclusion, that faster rates of productivity increase will provide the fundamental basis for competitive expansions in employment, is not supported by such modelling.

\section{Improving productivity}

Modelling should make use of parameters which are realistic and relate to historical experience. It is of little real value to force a model to produce some required result by the exogenous introduction of unreasonable assumptions. The productivity changes introduced in the modelling may be compared with the annual rates of change of total factor productivity for New Zealand in the recent past (Rose, 1990, p.5 infogram 2). These are as follows:

$\begin{array}{lr}\text { 1960s to } 1973 & 0.6 \text { percent } \\ 1973-79 & -2.5 \text { percent } \\ 1979-86 & 0.6 \text { percent } \\ \text { whole period } & -0.1 \text { percent }\end{array}$

A check on the extraordinary modelling technique of starting 6 years in the past and requiring retrospective increases in productivity may be obtained from data reported in infogram 5 (Rose, 1990, p.18). The total factor productivity in 1995 is 1.093 in the Prospects run (which, as we have noted above, has proved to be over-optimistic) and 1.210 in the "higher productivity" run. The first figure of 1.093 is a compounded annual rate of 0.81 percent over 11 years and the second figure of 1.210 is a compounded annual rate of 1.75 percent over 11 years. These numbers are close to the "doubling of the annual rate of productivity increase from 1 to 2 percent" referenced in the text.

If the Prospects productivity increase of 0.81 percent per year is assumed for the period up to the present (an already unrealistic assumption), then in order to generate the required increase in productivity of 1.210 by 1990 , the annual rate of productivity increase must be 2.86 percent for the remaining 5 years of the modelling 11-year time span. Whereas a 1.75 percent annual rate (generating an increase by a factor of 1.210 in 11 years) is some 3 times the recent New Zealand rates (the relatively high rate of 0.6 percent for 1979-86, see above), a 2.86 percent annual rate of productivity increase is almost 5 times that recent, observed value. 


\section{The experience of the manufacturing sector}

The manufacturing sector in New Zealand has collapsed in recent years. Between December 1985 and December 1989, the number of males employed has declined by 20 percent (from 217,300 to 173,800) and the number of females employed has declined by 25 percent (from 102,800 to 76,700 ). Hours worked in manufacturing dropped by 16.8 percent; from 538,357 in the March year 1985 to 452,265 in the March year 1989 (Department of Statistics 1990). An alternative measure of employment, from the Quarterly Employment Survey, which counts all those working in establishments which employ more than 2 full time equivalent paid employees, gave a drop in employment in manufacturing of 10,800 or 4.1 percent in the year to August 1990 (The Evening Post, 17 August 1990).

However the 2 reports model increasing employment in manufacturing from 1984 into the future. The 1988 Prospects (New Zealand Planning Council, 1988, infogram $6.10)$ has annual employment growth rates in manufacturing of 0.5 percent for 1984-92 and 0.9 percent for 1992-97. The 1990 report (Rose 1990, infogram 10) has an even higher increase in employment in manufacturing: from 1983/4 to 1994/95 the "higher productivity" run suggests an increase of 37,500 jobs in manufacturing, which is 9,900 more than the over-optimistic Prospects forecast. The Planning Council modelling simply reverses the observed trends.

I find this modelling of particular interest since, in 1981, I forecast the observed decline in manufacturing production in New Zealand following trade liberalisation using a global computer model, SARUM (referred to below) (Robinson 1981). One model experiment forecast that the proportion of machinery provided from local production could increase from around 75 percent in 1980 to 90 percent with less trade, but could decrease to around 15 percent by the year 2010 with more trade. These model runs included rather optimistic economic growth parameters; the output in physical units of machinery was forecast to double with less trade, and to almost halve with more trade. Another model experiment explored the consequences of free trade with Australia (such as CER). Whereas the forecast (again with somewhat optimistic economic growth assumptions) was for a 60 percent increase of employment in manufacturing with isolation, free trade reduced the increase to 16 percent.

The model suggested clearly that the New Zealand manufacturing sector would suffer under a policy of free trade, and that is exactly what has happened. With an appropriate model (which mirrors the real world), and with proper regard to existing trends, it is possible to gain some understanding of the macroeconomic trends which define the New Zealand economic experience.

The Planning Council's modelling of productivity in the manufacturing sector is not based on recent experience. Instead:

Forecast rates of change in total factor productivity for the manufacturing sector were drawn from the New Zealand Manufacturers' Federation survey undertaken as part of the consultation process. Participants were asked to estimate increases in capital and labour required for a $20 \%$ and a $50 \%$ rise in output, and these were used to estimate TFP (New Zealand Planning Council, 1988, p.39).

The meaning of such productivity change estimates is hard to grasp. Would productivity changes which have been based on the assumption of increased output simply automatically repeat such output increases when fed into a model? How do such estimates relate to a future world of increased employment (as forecast) when a key factor in recent gains in productivity is the shedding of labour? (New Zealand Planning Council, 1988 , p.39). Certainly the resultant forecasts of expansion in the manufacturing sector have proved to be quite the opposite of the observed behaviour. 
Reliance on opinion surveys is a dubious methodology for the forecasting of medium or long term trends. This may be a case of the blind leading the blind. Historically, business confidence has often proved a very poor guide to future events. Thus, for example, a period of pessimism in 1920-23 was followed by a period of economic growth. That growth engendered excessive optimism up to the time of the stock market crash of 1929 (Robinson 1990, pp.102-103). Both the initial pessimism and the following euphoria proved poor guides to the medium term prospects. Similarly, the recent (1987) stock market crash was preceded by a period of general optimism.

\title{
7. Multiple parameter changes in modelling
}

The sketch of future trends is referred to as a scenario in the foreword to the report (Rose 1990) and in a Planning Council summary of the report (New Zealand Planning Council, 1990). The mixed approach combines discussion, survey and discussion indications of productivity forecasts (in Prospects), non-model calculations and modelling using 2 medium-term models of the economy.

The models are linked in their use, and several parameter changes are made between the key model runs (as noted above). These are complex models, with a theoretical base and behavioural structure which are a mystery to most readers. I have noted on many occasions that the complex models which are made possible by the use of modern computational capabilities are often used as black-box propaganda tools. If this is to be avoided, the determinant mechanisms should be clear to the average discerning reader (Robinson, 1990, p.116). I believe that the modelling of this report fails such a test.

This is in part due to the multiple parameter changes between the Prospects base run (itself neither clear nor of any certain relevance) and the "higher capital and productivity" run. Without a very careful reading of the text, the reader may not understand the relative importance of the various parameter changes; this is particularly so when, as in the present case, the report makes assertions which are not based on the actual modelling. This confusion between the impacts of different parameter changes is a constant danger in this approach to scenario analysis, as I have noted from my experience with the OECD Interfutures project.

\begin{abstract}
"OECD Interfutures carried out similar runs using the [SARUM] model, but set their model experiments within a scenario structure which blurred the message somewhat." Scenarios which described free trade and protectionism were modelled using 2 exogenous changes to input parameters. Increased trade biases and lower economic growth rates were introduced as endogenous changes in the free trade (self sufficiency for the developing countries) model run. Free trade was then associated with poorer economic performance, but this was not an output generated by the workings of the model, rather it was a direct consequence of the changes to input parameters. "This was not a fair test of the model as far as trade policy alone is concerned" (Robinson 1990, p.133).
\end{abstract}

The model referred to here, the Systems Analysis Research Unit Model (SARUM) was used by Systems Analysis Research Unit staff to generate some most useful information, by varying one parameter at a time in order to carefully test some definite policy change, and to determine the resultant behaviour as described by the model (Robinson, 1990). I believe that such careful model experiments, involving one parameter change at a time, provide the best means of enriching a scenario analysis with the aid of complex computer models. Indeed, it is the description of the relative importance of the parameter changes in the "Increased investment" section of the report (Rose, 1990) which tells us that the entire employment growth is generated solely by the increased investment, and not by productivity improvements. 


\section{Conclusions from the modelling}

A careful reading of the 2 reports has established the following points:

(a) Estimates of employment requirements commenced in 1988 and ignored the significant loss of jobs between that date and the present.

(b) Modelling of productivity increases commenced with modelling which has proved unrealistic and overly optimistic, and assumed a further doubling of productivity.

(c) The model run commenced in 1984 with these increases in productivity in order to generate an optimistic result in 1995, thus ignoring the negative experiences of 198490.

(d) The model was instructed to produce full employment by 1995 - this was not a consequence of the modelling based on policy changes as represented by input parameters.

(e) Full employment was completely generated by additional capital investment.

To suggest that such modelling indicates the possibility of full employment by 1995 starting from the real New Zealand of 1990 is nonsense.

The model runs, when compared to actual experience, have shown clearly that full employment by 1995 is next to impossible, requiring an unbelievable reversal of trends, considerable additional capital investment and unbelievable increases in productivity. This is the unavoidable conclusion which must be reached from the modelling; the conclusions of the report are simply unprofessional wishful thinking.

\section{The Planning Council programme - "sustainable full employment with high incomes"}

The optimism of this modelling, compared to the observed reality, is common to Planning Council forecasts (Haywood 1980, Haywood and Cavana, 1986). I have noted previously (Robinson, 1988, p.104 and fig 10; Robinson, 1990, p.129) that:

Official forecasts usually reflect the blind wishful thinking of the time - the successful, long-lasting organisation will not bite the hand that feeds it. The New Zealand Planning Council, for example, regularly provides forecasts of unemployment which briefly follow the rising observed trend before levelling off, declining, and disappearing within about a decade. A few years later, unemployment in the real world has gone up. So they repeat the exercise, each time neglecting to present a graph showing the lack of agreement between any previous forecast and what has transpired. If they did, it would look just like an imaginative fireworks display, with the hopeful forecasts falling away to zero each time, but with the real world unemployment persistently mounting. I, along with others, saw in around 1976 that unemployment would be a feature of Western economies for a long time yet, but even up to the present time (13 years later in 1989) politicians continue to treat joblessness as a temporary phenomenon, replacing one stopgap scheme with another, and retreating to tautologies in which higher economic growth is called for in order to get the country back on its feet again. Many lives have been broken by this foolish and wilful ignorance as the blind lead the blind deeper into depression (Robinson, 1990, p.129). 
The tone of the introduction by Planning Council Chairman, Gary Hawke, and much of the discussion of the report itself, is dogmatic and ideological. The conclusion of this exercise in macroeconomics throws the onus of improvement onto the individual. Thus, for example, the summary states that "The return to full employment requires a commitment, and action, from each and all of us" (New Zealand Planning Council, 1990). I do not believe that the serious national economic situation is best dealt with by such exhortations to the many individuals who feel powerless in the face of overwhelming economic forces. This smacks of the growing tendency to blame the victim rather than to face squarely the need for appropriate collective action. It represents an abrogation of responsibility by national policy-makers.

Hawke states that: "This report by Dennis Rose is a key element in a major Planning Council programme to secure commitment by New Zealanders to achieving sustainable full employment with high incomes" (Rose, 1990, Foreward). The manner in which unjustified conclusions have been drawn from the modelling must raise serious concern regarding the purpose and value of the Planning Council programme.

It has been suggested to me that the report has a certain value in that it chooses to "think positive", and follows an optimistic approach which insists (whether or not the facts support the contention) that full employment can be achieved. That attitude suggests further that pessimistic realism may be in accord with the facts, but is not very productive.

As a scientist, I believe that modelling should provide a realistic representation of the real world. A model must fit observed data before reaching conclusions or making forecasts of expected happenings; and the model must then be judged by the success or failure of such forecasts. Only then will modelling provide useful understanding and guidance. If those of us who thought, in the mid-1970s, that unemployment was a long term feature of modern developed societies had been listened to, perhaps policy would have been developed to face the problem squarely and to develop solutions. Instead of this, it has been continually wished away.

\section{References}

Haywood, E. (1980) Forecasting the economy in the eighties. Wellington, New Zealand Planning Council.

Haywood, E. and Cavana, R.Y. (1986) A macro-economic model and scenarios to 1995. Wellington, New Zealand Planning Council (Planning Paper No. 24).

New Zealand Planning Council (1988) National Sectoral Programme Prospects: economic and social trends to 1997. Wellington.

New Zealand Planning Council (1990) Summary of the fully employed high income society. Wellington.

Robinson, J.L. (1981) Trade pattern scenarios investigated by SARUM. Wellington, Commission for the Future. (Technical Report 81/2).

Robinson, J.L. (1988) Maori futures - the paths ahead; two scenarios of development of Maoridom in Aotearoa/New Zealand. Report to the Royal Commission on Social Policy.

Robinson, J.L. (1990) Excess capital. Martinborough, Technology Monitoring Associates. 
272 John Robinson

Rose, D. (1990) The fully employed high income society. Wellington, New Zealand Planning Council. 